\title{
Immunohistochemical expression of BRCA 1 and BRCA2 in a cohort of Ugandan men with prostate cancer: an analytical cross-sectional study
}

\author{
PatrickT. Amsi' ${ }^{1}$ James J. Yahaya ${ }^{2^{*}}\left(\mathbb{0}\right.$, Sam Kalungi $^{3}$ and Michael Odida ${ }^{1}$
}

\begin{abstract}
Background: Mutation of the tumour suppressor genes BRCA1 and BRCA2 is thought to cause early development of prostate cancer which has poor prognosis. The purpose of this study was to determine the expression of BRCA1/2 and correlate it with clinicopathological factors for patients with prostate cancer in uganda.

Methods: Retrospectively, we used immunohistochemistry to evaluate the expression of BRCA1/2 antibodies in tissue blocks of 188 patients with prostate cancer who were diagnosed between January 2005 and December 2014 in the Department of Pathology, Makerere College of Health Sciences. The Chi-Square test was used to determine the association of the categorical variables, whereas t-test was used to compare groups of mean of the variables in the study.

Results: Expression of BRCA1 and BRCA2 was found in $26.1 \%$ and $22.9 \%$ cases, respectively. Co-expression of BRCA1 and BRCA2 was found in only 7.4\%. Gleason score was associated with expression of BRCA1 and BRCA2 $(P=0.013$, $P=0.041$, respectively). Age was not associated with BRCA1 and BRCA2 expression; $P=0.543, P=0.091$, respectively. Likewise, PSA was not associated with BRCA1 and BRCA2 expression; $P=0.446, P=0.399$, respectively.

Conclusion: BRCA1 and BRCA2 proteins in this study were expressed more in cases with poorly differentiated prostate cancer than in cases with either well or moderately differentiated prostate cancer. Co-expression of BRCA1 and BRCA2 proteins in the same patient in our study was 3 times less than either BRCA1 or BRCA2 alone.
\end{abstract}

Keywords: Prostate cancer, BRCA1, BRCA2, Immunohistochemistry, Kampala

\section{Background}

The breast cancer susceptibility genes (BRCA1 and BRCA2) are cellular proteins involved in deoxynucleic acid (DNA) repair. They are normally expressed in the breast, ovaries, prostate and other tissues [1]. BRCA1 and BRCA2 help to repair damaged DNA or enhance apoptosis if DNA cannot be repaired [2]. They are involved in the repair of chromosomal damage with an important

\footnotetext{
*Correspondence: jayame76@gmail.com

${ }^{2}$ Department of Biomedical Science, College of Health Sciences (CHS),

University of Dodoma, P.O. BOX 395, Dodoma, Tanzania

Full list of author information is available at the end of the article
}

role in the error-free repair of DNA double-strand breaks $[1,3]$. BRCA $1 / 2$ genes play a role in ensuring the stability of the cell's genetic material [2-4]. Men with BRCA1/2 mutations have a higher risk of developing prostate cancer (PCa). Studies have shown that the risk of men to develop PCa in families with breast cancer is threefold as compared to the families without a history of breast cancer $[5,6]$.

Like other gene mutations, BRCA1 and BRCA2 mutations are rare in the general population. In the USA, about 1 in 400 people have BRCA1/2 mutation [7, 8]. Prevalence of BRCA1/2 varies by ethnic group. People of Ashkenazi Jews descent have a high prevalence of 
BRCA1 and BRCA2 mutations than people in the general population globally. Other ethnic groups that have been reported to have a significant proportion of BRCA1 and BRCA2 mutations include the Norwegian, Dutch and Icelandic peoples [9].

Determination of BRCA1 and BRCA2 mutations among patients with $\mathrm{PCa}$ is crucial for prognostication and use of novel targeted therapy. Studies have shown that expression of BRCA1/2 in patients with $\mathrm{PCa}$ is associated with high Gleason score at diagnosis and the majority of them have poor prognosis [3, 4, 9]. The expression of these proteins in patients with low and moderate tumour grade is usually low. Additionally, it has been reported that patients with PCa expressing BRCA1/2 have a high chance of having recurrence of the disease as well as poor biochemical progression-free survival (BCPFS) [10-12]. Where patients with PCa are diagnosed with high Gleason score, investigation of the expression of BRCA1/2 would be of paramount importance for determining prognosis of the patients. Uganda is one of the countries in Africa with high incidence of $\mathrm{PCa}$ and besides, the majority of patients in the country are diagnosed with high Gleason score (poorly differentiated tumour). Yahaya et al. and Okuku et al. in two different studies reported $73.1 \%$ and $54.8 \%$ of patients with PCa in Uganda had Gleason score $\geq 8[13,14]$. In other two studies done in Uganda by Yahaya, it was reported that $44.6 \%$ and $55.9 \%$ of the patients with PCa had Gleason score $\geq 8[15,16]$. In all the four studies, none of them involved determining of expression of either BRCA1 or BRCA2 protein.

This study aimed at determining the prevalence of BRCA1 and BRCA2 proteins using immunohistochemical (IHC) technique in patients with PCa in Uganda. The second objective was to determine the association of the two proteins expression with age, pre-treatment prostate-specific antigen (PSA) and Gleason score as the clinicopathological prognostic factors. To the best of our understanding, this is the first study to be done in Uganda for investigating the prevalence of expression of BRCA1/2. The findings of this study will be used as reference in justifying the need for evaluating these proteins in patients with $\mathrm{PCa}$ within the country so as to improve the clinical outcomes of the patients through the use of targeted therapy.

\section{Methods}

\subsection{Study design and setting}

This was a cross-sectional analytical laboratory-based study. The study was conducted in the Department of Pathology at Makerere College of Health Sciences (MakCHS), Kampala, Uganda. The laboratory serves the roles of teaching, research and offers diagnostic as well as autopsy services for the whole country and the neighbouring countries such as Rwanda, Democratic Republic of Congo, Kenya and South Sudan. The Department receives and processes an average of 8,000 tissue biopsies per year.

\subsection{Patients' information}

The patients included in this study were diagnosed with prostate cancer on histological basis from January 2005 to December 2014. The laboratory request forms and information from the medical records regarding the clinical history of the patients were used to identify the required cases for the study. Abstraction of data on age of the patients at diagnosis and prostate-specific antigen (PSA) levels at diagnosis was done from medical records and supplemented with laboratory request forms.

\subsection{Sampling procedure}

All the available formalin-fixed paraffin-embedded (FFPE) tissue blocks from the patients that met the inclusion criteria were selected and included in the study. The inclusion criteria were all cases with complete clinical information, all cases with a histopathological diagnosis and all cases with FFPE tissue blocks which had enough tissue. On the other hand, the exclusion criteria were all cases whose FFPE were spoilt by insects and all cases with inadequate tissue materials in the FFPE tissue blocks. Accession laboratory numbers found on the laboratory requisition forms were used to retrieve the FFPE tissue blocks. For a period of 10 years, from 2005 to 2014, a total of 215 patients with prostate cancer were histologically diagnosed. However, $12.6 \%(n=27)$ of them were excluded from the study after failing to meet the inclusion criteria set for the study. We conducted a standardized histopathologic review for Gleason score. Gleason score was obtained after re-examination of the cases using haematoxylin- and eosin-stained tissue sections. Gleason scores of the prostate tumours were categorized into $\leq 7$ and $\geq 8$ subgroups. This cut-off was chosen based on clinical experience and prior literature, suggesting that clinical outcome for Gleason score $\leq 7 \mathrm{PCa}$ differs significantly to that for Gleason score $\geq 8 \mathrm{PCa}$. The FFPE tissue blocks were of different types of biopsies including retropubic radical prostatectomy (RRP), transurethral resection of prostate (TURP) and needle core biopsies.

\subsection{Immunohistochemical staining for BRCA1 and BRCA2 proteins}

Immunohistochemical (IHC) staining was performed in all the 188 selected cases using the FFPE tissue blocks which were cut using a microtome (4 microns) and mounted onto charged slides (Starfrost) and dried 
overnight at $38{ }^{\circ} \mathrm{C}$. The sections were deparaffinized in two changes of xylene for $5 \mathrm{~min}$ each. Hydration was done in two changes of $100 \%$ ethanol for $3 \mathrm{~min}$ each, 95\% and $80 \%$ ethanol for 1 min each. Then, the sections were rinsed in distilled water. The sections were placed in $0.01 \mathrm{M}$ tris buffer solution (TBS), $\mathrm{pH} 6.0$ antigen retrieval solution until temperature reached $95{ }^{\circ} \mathrm{C}$ for $2 \mathrm{~min}$. The sections were rinsed in phosphate buffer solution (PBS). Endogenous peroxidase blocking was performed by placing the sections in $3 \%$ of $\mathrm{H}_{2} \mathrm{O}_{2}$ for $30 \mathrm{~min}$. Incubation of the sections with BRCA1 (polyclonal MS110, Abcam, USA) and BRCA2 (polyclonal ab27976, Abcam, USA) antibodies simultaneously at dilution of 1:10 overnight at $4{ }^{0} \mathrm{C}$ was done.

The sections were rinsed in PBS for $4 \mathrm{~min}$. Then, the sections were stained with DAB chromogen (Envision Flex, Dako, Denmark) followed by counterstaining with haematoxylin. The positive control was tissue from invasive ductal carcinoma of the breast, whereas negative control was tissue of the hippocampal part of the human brain. BRCA1 and BRCA2 status was considered positive when tumour cells stained golden brown. The positive results were reported based on intensity of staining and percentage of tumour cells. Scores for intensity ranged from $0-3$. Then, we multiplied the percentage of tumour cells with the intensity in order to obtain the immunoreactive score which ranged from 0 to 12 .

The immunoreactive scores were as follows: 0: negative, 1-3: weakly positive, 4-6: moderately positive and 8-12: strongly positive [17]. Both the histological and IHC stained tissue slides were examined by two independent expert pathologists who were blinded of the clinical characteristics of the patients.

\subsection{Data analysis}

Data collected were cross-checked and edited for any errors, coded and entered into the computer using Epi Data version 3.2. Then, they were exported into STATA version 16.0 for analysis. We evaluated the association of BRCA1 and BRCA2 expression based on immunohistochemistry with age of the patients, pre-treatment PSA level and Gleason score. Continuous variables (age and PSA were summarized in mean \pm standard deviation (SD). Student's t-test was used to determine the association of age of the patients at diagnosis and PSA with positivity of BRCA1 and BRCA2. Pearson's chi-square test was used to determine the association between Gleason score and the expression of BRCA1 and BRCA2. A two tailed $P$ value $<0.05$ at $95 \%$ confidence interval was considered for statistical significance.

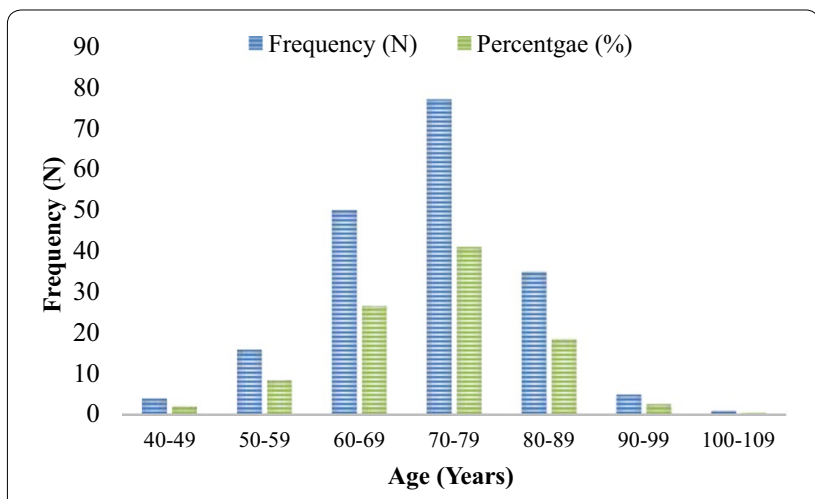

Fig. 1 Distribution of the patients by age group

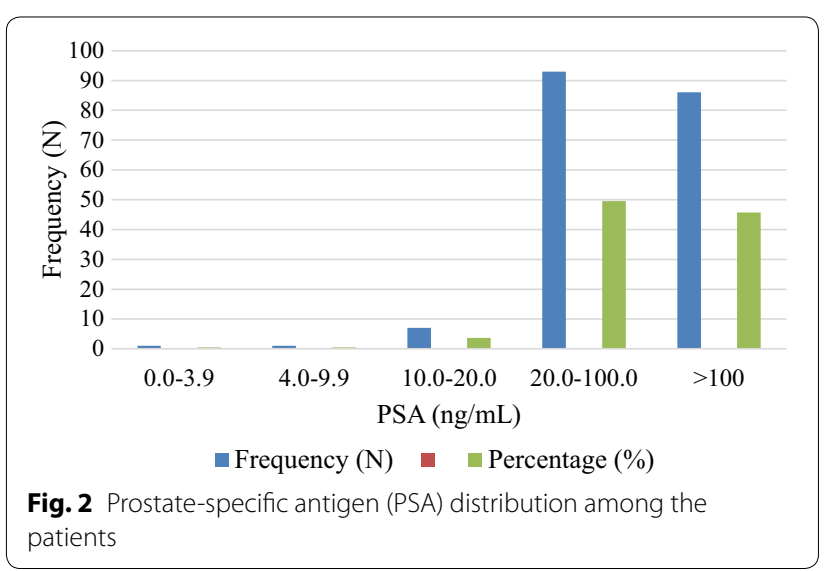

\section{Results}

\subsection{Patients' Characteristics}

The mean age $\pm S D$ of the patients was $71.4 \pm 9.92$ years. Most of the patients $41 \%(n=77)$ had age ranging between 70 and 79 years. A very few patients $2.7 \%(n=5)$ had age $<50$ years (Fig. 1). The mean $\pm(\mathrm{SD})$ for pre-treatment PSA level was $434.06 \pm 625.81 \mathrm{ng} / \mathrm{mL}$. Most of the patients $49.5 \%(n=93)$ had PSA level ranging from 20 to $100 \mathrm{ng} / \mathrm{mL}$ and only $1 \%(n=2)$ of all the patients had PSA level $<10 \mathrm{ng} / \mathrm{mL}$ (Fig. 2). The majority of the patients 82.4\% $(n=155)$ had high Gleason score $(\geq 8)$ and the remaining $17.6 \%(n=33)$ had Gleason score $\leq 7$.

\subsection{Prevalence of BRCA1 and BRCA2 Immunohistochemical Expression}

The expression of BRCA1, BRCA2 and co-expression of BRCA1, and BRCA2 was $26.1 \%(n=49), 22.9 \%(n=43)$ and $7.4 \%(n=14)$, respectively (Fig. 3$)$. Our findings in this study show that BRCA1 protein was expressed relatively more than BRCA2 proteins and even higher than the co-expression of BRCA1 and BRCA2. The striking 


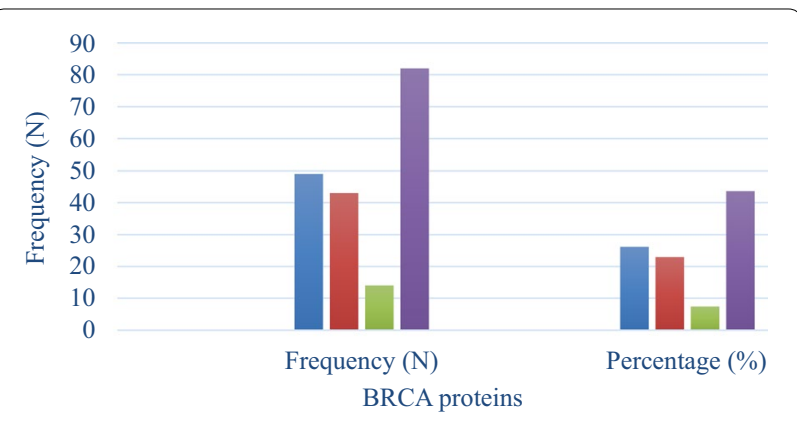

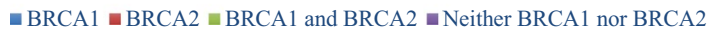

Fig. 3 Expression of $B R C A 1$ and $B R C A 2$ proteins among prostate cancer cases

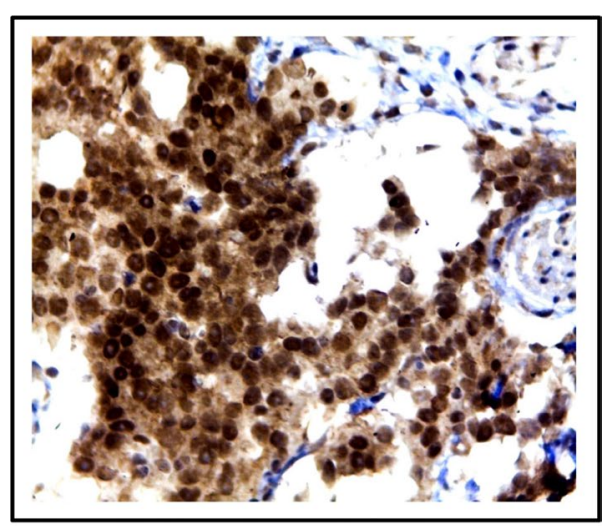

$\mathbf{a}$

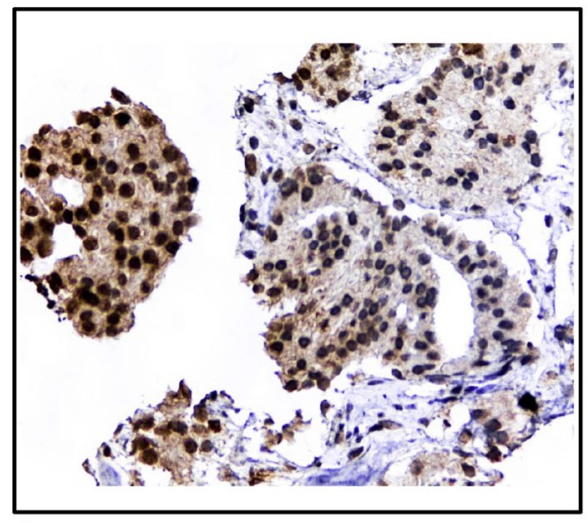

b

Fig. 4 a BRCA1 expression in a case with Gleason score $10(5+5)$. BRCA1 antibody shows both strong nuclear and cytoplasmic staining $(I H C, \times 100)$. b BRCA2 expression in a case with Gleason score $9(5+4)$. BRCA2 has strong nuclear staining and foci with weak cytoplasmic staining $(\mathrm{IHC}, \times 100)$

finding in this study was that, of the PCa cases expressing BRCA proteins, there were fewer cases that could coexpress BRCA1 and BRCA2. Both BRCA1 and BRCA2 antibodies were showing both cytoplasmic and nuclear staining characteristics (Fig. $4 a$ and b).

We determined the association of age of the patients, pre-treatment PSA and Gleason score with the IHC expression of BRCA1, BRCA2 and co-expression of BRCA1 and BRCA2. The mean age of the patients whose specimens were expressing BRCA1 was slightly higher than the mean age in patients whose specimens were not expressing BRCA1 antibody (72.6 years versus 70.6 years). However, the difference of expression of BRCA1 protein between the specimens of the patients expressing the antibody and those without expressing it was not statistically significant $(P=0.543)$ (Table 1$)$.

Patients expressing BCRA1 in this study had a mean pre-treatment PSA higher than that in patients whose specimens were not expressing the antibody (449.8 versus $389.4 \mathrm{ng} / \mathrm{mL}$ ). Although there was a difference for the mean PSA between the two groups compared, however, the difference was not statistically significant $(P=0.446)$. Tumour differentiation which is frequently determined by using Gleason score in this study was associating with the expression of BRCA1 antibody. The positivity of the specimens for the patients with Gleason score $\geq 8$ (poorly differentiated $\mathrm{PCa}$ ) was markedly higher than the positivity in the specimens of the patients with Gleason score $\leq 7$ (well to moderately differentiated PCa) (42 cases versus 7 cases). The difference in positivity between well-moderately and poorly differentiated cases was statistically significant $(P=0.013)$.

Regarding positivity of BRCA2 antibody in this study, it was found that the median age of the patients expressing the antibody was slightly higher than that in the patients not expressing BRCA2 protein ( 74 years versus 71 years). The association between age and the expression of BRCA2 antibody was not statistically significant $(P=0.091)$ (Table 2$)$. The median PSA among patients expressing BRCA2 antibody in this study was relatively lower than the median PSA in whom the specimens were not expressing the antibody (363.2 versus $455.1 \mathrm{ng} / \mathrm{mL}$ ). The association between PSA and BRCA2 expression was not statistically significant $(P=0.399)$. Gleason score was associated with the expression of BRCA2 antibody in this study $(P=0.041)$. There were quite many specimens expressing BRCA2 in patients with poorly differentiated PCa (Gleason score $\geq 8$ ) as compared to the positivity of specimens with well to moderately differentiated PCA (Gleason score $\leq 7$ ) (3 cases versus 40 cases).

Table 3 shows the association between age, PSA Gleason score and the co-expression of BRCA1 and BRCA2. The co-expression of the two antibodies was not associated with age of the patients at diagnosis $(P=0.845)$ regardless of the slight difference of the median age between the two groups (71.9 years versus 72.3 years). 
Table 1 Association of BRCA1 with age, PSA and Gleason score

\begin{tabular}{|c|c|c|c|c|}
\hline \multirow[t]{2}{*}{ Variables } & \multicolumn{3}{|l|}{ BRCA1 status } & \multirow[t]{2}{*}{$P$} \\
\hline & Positive & Negative & $95 \% \mathrm{Cl}$ & \\
\hline Number: n (\%) & $49(26.1)$ & $139(73.9)$ & & \\
\hline Age (years): mean (SD) & $72.6(10.410)$ & $70.6(8.445)$ & $-4.264-2.252$ & $0.543^{\dagger}$ \\
\hline PSA (ng/mL): mean (SD) & $449.8(628.02)$ & $389.4(623.780$ & $-265.930-145.338$ & $0.446^{\dagger}$ \\
\hline \multicolumn{5}{|l|}{ Gleason score, n (\%) } \\
\hline$\leq 7$ & $7(21.2)$ & $26(78.8)$ & $1.293-3.703$ & $0.013^{*}$ \\
\hline$\geq 8$ & $42(27.1)$ & $113(72.9)$ & & \\
\hline
\end{tabular}

† Student's $t$-test, ${ }^{*}$ Pearson's chi-square test

$P S A$ Prostate-specific antigen, $B R C A 1$ breast cancer antigen $1, C l$ confidence interval, $S D$ standard deviation, $P P$ value

Table 2 Association of BRCA2 with age, PSA and Gleason score

\begin{tabular}{|c|c|c|c|c|}
\hline \multirow[t]{2}{*}{ Variables } & \multicolumn{3}{|l|}{ BRCA2 status } & \multirow[t]{2}{*}{$P$} \\
\hline & Positive & Negative & $95 \% \mathrm{Cl}$ & \\
\hline Number: n (\%) & $43(22.9)$ & $145(77.1)$ & & \\
\hline Age (Years): mean (SD) & $74.6(10.27)$ & $71.7(9.76)$ & $-0.468-6.298$ & $0.091^{\dagger}$ \\
\hline PSA (ng/mL): mean (SD) & $363.2(575.10)$ & $455.1(640.46)$ & $-306.419-122.674$ & $0.399^{\dagger}$ \\
\hline \multicolumn{5}{|l|}{ Gleason score, n (\%) } \\
\hline$\leq 7$ & $3(9.1)$ & $30(90.9)$ & $0.083-0.994$ & $0.041^{*}$ \\
\hline$\geq 8$ & $40(25.8)$ & $115(74.2)$ & & \\
\hline
\end{tabular}

PSA Prostate-specific antigen, $B R C A 2$ breast cancer antigen 2, $C l$ confidence interval, $S D$ standard deviation, $P P$ value

† Student's t-test, ${ }^{*}$ Pearson's chi-square test

Table 3 Association of co-expression of BRCA1 and BRCA2 with age, PSA and Gleason score

\begin{tabular}{|c|c|c|c|c|}
\hline \multirow[t]{2}{*}{ Variables } & \multicolumn{3}{|c|}{ Co-expression of BRCA1 and BRCA2 } & \multirow[t]{2}{*}{$P$} \\
\hline & Positive & Negative & $95 \% \mathrm{Cl}$ & \\
\hline Number: n (\%) & $14(7.4)$ & $174(92.6)$ & & \\
\hline Age (years): mean (SD) & $71.9(7.78)$ & $72.3(10.09)$ & $-4.912-5.994$ & $0.845^{\dagger}$ \\
\hline PSA (ng/mL): mean (SD) & $268.3(520.18)$ & $447.4(632.93)$ & $-522.020-163.827$ & $0.304^{\dagger}$ \\
\hline \multicolumn{5}{|l|}{ Gleason score, n (\%) } \\
\hline$\leq 7$ & $2(7.4)$ & $25(92.6)$ & $0.164-3.610$ & $0.733^{*}$ \\
\hline$\geq 8$ & $12(12.4)$ & $85(87.6)$ & & \\
\hline
\end{tabular}

PSA Prostate-specific antigen, $B R C A$ breast cancer antigen, $C l$ confidence interval, $S D$ standard deviation, $P P$ value

† Student's t-test, ${ }^{*}$ Pearson's chi-square test

Also the mean PSA in the specimens of patients in whom there was no co-expression of BRCA1 and BRCA2 was found to be relatively higher than that of the specimens of the patients showing co-expression of both BRCA1 and BRCA2 (447.4 $\mathrm{ng} / \mathrm{mL}$ versus $268.3 \mathrm{ng} / \mathrm{mL}$ ) and the association was not statistically significant $(P=0.304)$.
Likewise, tumour grade was found to be not associated with co-expression of BRCA1 and BRCA2 antibodies $(P=0.733)$ despite that there was a noticeable difference in co-expression between cases with poorly differentiated tumour (Gleason score $\geq 8$ ) and those with well to moderately tumour (Gleason score $\leq 7)(12$ cases versus 2 cases). 


\section{Discussion}

Immunohistochemical detection of BRCA1 and BRCA2 proteins in patients with $\mathrm{PCa}$ is easy and cost-effective for countries where molecular testing is still a challenge. In this study, we made a hypothesis that association of these gene proteins which are among the key genes mutated in the process of developing of $\mathrm{PCa}$ with clinicopathological prognostic factors such as Gleason score, age and PSA among others may help to determine the prognosis of the disease.

The prevalence of expression of BRCA1 protein in this study was $26.1 \%$. This was higher than $15 \%$ and $1.7 \%$ that were reported in the USA and Israel, respectively [17, 18]. The low prevalence of $1.7 \%$ for expression of BRCA1 which was reported by Giusti among the Ashkenazi patients with $\mathrm{PCa}$ in Israel could have been attributed to a number of factors including different methods of detection between the two studies, low level of hereditary type of PCa among the Ashkenazi men and also the difference in aggressiveness of the disease for the two races. All these factors might have contributed greatly to the difference in expression of BRCA1 protein. Moreover, the study which was done in the USA used monoclonal BRCA1 antibody compared to polyclonal BRCA1 antibody that was used in the current study. Therefore, the difference in specificity between the two different types of antibodies used for the two studies could be the reason for the difference in the expression of the antibody for the studies. The difference in clonality of the antibodies between the two studies greatly resulted to the substantial difference in expression.

In 2011, Rabiau et al. reported the prevalence of expression of BRCA1 protein detected by means of IHC as $22.4 \%$ which is lower than $26.1 \%$ was found in this study [19]. The large percentage of patients with high Gleason score in our study compared to the small percentage of patients with high Gleason score in their study contributed for the difference in expression of the antibody between the two studies. This is because studies have shown that poorly differentiated $\mathrm{PCa}$ is associated with high expression of BRCA1 protein [20]. Also the subjectivity in interpretation of the positivity of the antibody may have led to the existing difference in the level of expression.

The prevalence of expression of BRCA2 tumour suppressor gene in patients with $\mathrm{PCa}$ is lower than BRCA1 $[21,22]$. Detection of both BRCA $1 / 2$ proteins by means of IHC gives a high prevalence of expression compared to detection by using molecular tests such as real timequantitative polymerase chain reaction (RT-qPCR) which are more specific as it was reported in the studies in the USA and Israel. These two previous studies used RTqPCR test to determine the prevalence of mutation of
BRCA2 whereby $15 \%$ and $1.7 \%$ were reported, respectively $[17,18]$. At different occasions, Stephen et al. and Tryggvadottir et al. reported $2.3 \%$ and $5.7 \%$, respectively $[23,24]$.

In the study of Tryggvi et al., it was reported that the prevalence of expression of BRCA2 in the controls was $25 \%$ slightly higher than $22.9 \%$ that was found in our study and $38 \%$ in the cases, also higher than the prevalence in our study [25]. The difference in prevalence could have resulted from the two reasons: the first reason is the difference in the methodology. The previous study employed use of tissue microarray (TMA) technique, which by far, provides high positivity rate of the marker based on the reason that selection of the tissue areas to be stained is optimal. The second reason is that the previous study used the antibody for $\mathrm{C}$-and $\mathrm{N}$-terminal of the BRCA2 protein. These give more positivity compared to the approach used in the current study. The heterogeneous nature of the expression of these tumour suppressor genes has also reported to contribute greatly to the difference in prevalence of expression for the different studies done $[19,25]$.

In our study, we analysed the association of BRCA1 and BRCA2 proteins expression with age of the patients at diagnosis, pre-treatment PSA and Gleason score as the clinicopathological prognostic factors in our study. Besides, we went further and did analysis of the coexpression of the two antibodies with the prognostic factors. We considered a case to have co-expression of BRCA1 and BRCA2 if it could stain for both proteins simultaneously.

Regarding the association of BRCA1/2 protein based on IHC detection method, the results seem to be contradicting. Edwards et al. reported that BRCA2 protein expression was higher in cases aged $\leq 65$ years, but the difference was not statistically significant $(P=0.08)$ [23]. This is contrary to what was found in the present study where cases expressing BRCA2 had higher median age than those not expressing the protein $(74$ years versus 71 years) and the difference was not statistically significant $(P=0.091)$ but is in agreement with the observation in the study conducted by Kirchhoff et al. [26]. In their study, it was reported that presence of BRCA2 expression was higher in old patients compared to younger patients.

Among the possible reasons that can explain these contradicting results, it is the difference of the age of onset of the diseases for the different races. In a study done on the African population, it was found that PCa cases in Africa present approximately a decade earlier than it is the case in western countries [27]. In the present study, it was observed that only few cases $(<20 \%)$ were aged less than 64 years. Therefore, this could have attributed to the lack of association between BRCA2 expression and age 
of the patients at diagnosis. This shows that there was no significantly increased risk for early onset prostate cancer in BRCA1 expression. Besides, the small proportion of patients with early onset of $\mathrm{PCa}$ in this study could also be due to lack of screening programmes in the country $[14,15]$. This causes delayed detection of the diseases reflected by the small percent of cases with early onset of the disease in the present study.

PSA has been studied extensively as one of the clinical biomarkers that can predict the clinical outcomes of the patients with PCa $[28,29]$. However, its ability to predict aggressiveness and progression of the disease is controversial due to the fact that there are many conditions which may cause rising of its level. Neil et al. reported that rising of PSA before diagnosis of $\mathrm{PCa}$ is associated with poor clinical outcomes. Additionally, they reported that short doubling time of PSA among patients with $\mathrm{PCa}$ is associated with biochemical recurrence and even poor prognosis [30, 31]. In settings where screening of $\mathrm{PCa}$ is not routinely done, patients are usually diagnosed with very high PSA level. This is one of the factors explaining the poor outcomes of patients with $\mathrm{PCa}$ in settings where screening is not a routine practice where Uganda is included $[14,15]$.

Fiorentino et al. reported the association of BRCA1 expression with PSA. Patients with BRCA1-positive had median PSA level of $27.0 \mathrm{ng} / \mathrm{mL}$ ) higher than median PSA level of $10.2 \mathrm{ng} / \mathrm{mL}$ ) in patients who were BRCA1negative and the difference was statistically significant $(P=0.0056)$ [17]. This finding is different from our finding which showed that although there was higher median PSA in BRCA1-positive cases compared to BRCA1-negative cases $(449.8 \mathrm{ng} / \mathrm{mL}$ versus $389.4 \mathrm{ng} / \mathrm{mL})$, but the difference was not statistically significant $(P=0.446)$. The difference could have been due to the fact that most our cases had high PSA level unlike the patients in the previous study.

When we analysed the association between BRCA2 protein expression and the PSA level, we found that the median PSA level for BRCA2-negative cases was higher than the BRCA2-positive cases $(455.1 \mathrm{ng} / \mathrm{mL}$ versus $363.2 \mathrm{ng} / \mathrm{mL}$ ). This was a converse trend of the level of PSA in terms of progression of the disease, and the difference was not statistically significant $(P=0.399)$. This finding is similar to the finding in the study of Thorne et al. which also reported that there was no association between PSA and BRCA2 protein expression in patients with PCa $(P=0.006)$ although BRCA2-positive cases had higher median PSA than BRCA2-negative cases (56.2 ng/ $\mathrm{mL}$ versus $100 \mathrm{ng} / \mathrm{mL}$ ) [32]. In another study of Gallager et al., it was found that there was no association between PSA and BRCA2 mutation in patients with BRCA2 wild-type ( $P=0.99)$ and those with BRCA2 mutant gene and both groups had the same median PSA of $7 \mathrm{ng} / \mathrm{mL}$ [3].

There was a significant statistical difference between BRCA-positive with Gleason score $\leq 7$ and BRCA-positive cases with Gleason score $\geq 8(P=0.013)$. There were many BRCA1-positive with Gleason score score $\geq 8$ than BRCA1-positive cases with Gleason score $\leq 7$ (42 cases versus 7 cases). This was similar to the finding reported in the study of Fiorentino et al. who reported that BRCA1positivity was associated with Gleason score $(P=0.004)$. They found that cases with Gleason score $8-10$ were 21 compared to Gleason score $4-6,3+4=7$ and $4+3=7$ which comprised 10, 19 and 10 BRCA1-positive cases, respectively [17].

The high Gleason score for BRCA1 and BRCA2 positive cases found in the current study was also consistently observed in Castro's study which indicated aggressive form of prostate cancer for both BRCA1 and BRCA2 with poor clinical outcome [33]. The association of BRCA2 protein expression with Gleason score in this study was also in agreement with the findings in the studies of Tryggvadottir et al. $(P=0.001)$ and Rabiau et al. $(\mathrm{P}<0.012)[19,24]$. Moreover, it has been reported that PCa patients containing BRCA1/2 gene are more likely to have poor survival, recurrence and metastasis $[4,9]$.

This association could be explained by the fact that PCa with BRCA mutations have abnormal epithelial cells with high proliferative rate and extensive genetic instability which eventually could lead to inefficient DNA repair mechanisms. For example, Fiorentino et al. reported that BRCA1 may help to induce cell cycle arrest to allow for DNA repair [17]. However, some studies have reported the contradicting results. Edwards et al. reported that there was no association between BRCA2 status and grade of prostate cancer $(P=0.071)$ [10]. The findings obtained from this study particularly the association of Gleason score with BRCA1/2 using IHC detection method should pave for the need of having studies that involve large sample size as well as controls in countries where testing for mutations is challenging due to a number of factors including financial constraints and lack of enough and competent trained individuals to run the tests.

\subsection{Limitations of the study}

Because of using retrospective data, we were not able to obtain data on lymph node metastasis and other distant organs which lead to failure to run association of such important prognostic factors and expression of BRCA1/2 genes. Another limitation of our study was inability to 
perform molecular testing of mutation of the two genes due to financial constraints.

\section{Conclusions}

BRCA1 protein was expressed more than BRCA2 protein in this study. Co-expression of both BRCA1 and BRCA2 was seen in few cases compared to expression of either BRCA1 or BRCA2. Expression of BRCA1 and BRCA2 was higher in cases with poorly differentiated $\mathrm{PCa}$ (Gleason score $\geq 8$ ) than in cases with well and moderately differentiated PCa (Gleason score $\leq 7$ ). Gleason score was associated with BRCA1 and BRCA2 protein expression $(P=0.013, P=0.041$, respectively).

Expression of both BRCA1 and BRCA2 in the same case was found to have significantly lower proportion than expression of one of the two proteins. This may be hypothesized that mutation of both BRCA1 and BRCA2 in the same case rarely occurs. This needs a large-scale study in the future which has to include other refined methods of detecting presence of mutation of the proteins such as detection of the mutation and amplification methods. This would greatly help in the process of determining prognosis of the patients using molecular markers which may be used for targeted therapy as well. This will help to improve the survival of patients significantly.

\section{Abbreviations \\ PCa: Prostate cancer; PSA: Prostate-specific antigen; IHC: Immunohistochem- istry; TMA: Tissue microarray; DAB: Diaminobenzidine; FFPE: Formalin fixed paraffin embedded.}

\section{Acknowledgements}

We thank the Head of Department of Pathology for her support during the time of preparing this work. We also thank the laboratory technicians at the department for helping us to retrieve and prepare all the materials that were required for the study.

\section{Author contributions}

P.T. A. conceptualized the study, performed curation of the data, performed statistical analysis and wrote the first draft, J. J. Y. organized the manuscript, performed in-depth search of literature and reviewed the manuscript critically, S. K. designed the study, reviewed the manuscript critically and supervised the research, and M. O. designed the study, reviewed the manuscript critically and supervised the research. All authors read and approved the final manuscript.

\section{Funding}

This research did not receive fund to support.

\section{Availability of data and materials}

The datasets generated during and/or analysed during the current study are available from the corresponding author on reasonable request.

\section{Ethics approval and consent to participate}

Ethical clearance and approval of the study was sought from the institution review board (IRB) of the School of Biomedical Science (SoB) of Makerere College of Health Sciences (MakHS). A reference number HDR-IRB-605 for the study was provided. Written consent to use the specimens of the patients included in this study was obtained from the chairperson of the IRB. The consent requires maintaining maximum confidentiality for the information of the patients whose specimens were used for the research as per guidelines for research stipulated by the institution which conform with the international guidelines for research including those of the Helsinki Declaration.

\section{Competing interests}

All authors have no competing interests related to this work to be disclosed.

\section{Consent for publication}

Consent for publication of the patients' clinical information and pathologic findings was obtained from the patients.

\section{Author details}

${ }^{1}$ Department of Pathology, School of Biomedical Sciences, Makerere University, Kampala, Uganda. ${ }^{2}$ Department of Biomedical Science, College of Health Sciences (CHS), University of Dodoma, P.O. BOX 395, Dodoma, Tanzania.

${ }^{3}$ Mulago National Specialized Hospital, Mulago Uphill, Kampala, Uganda.

Received: 4 February 2020 Accepted: 25 September 2020

Published online: 19 November 2020

\section{References}

1. Sundararajan S, Ahmed A, Goodman OB Jr (2011) The relevance of BRCA genetics to prostate cancer pathogenesis and treatment. Clin Adv Hematol Oncol 9(10):748-755

2. Friedenson B (2007) The BRCA1/2 pathway prevents hematologic cancers in addition to breast and ovarian cancers. BMC Cancer 7:152

3. Gallagher DJ, Gaudet MM, Pal P, Kirchhoff T, Balistre ri L, Vora K, et al (2010) Germline BRCA mutations denote a clinicopathologic subset of prostate cancer. Clin Cancer Res 16(7):2115-2121

4. Jenzer M, Kess P, Nientiedt C, Endris V, Kippenberger M, Leichsenring J et al (2019) The BRCA2 mutation status shapes the immune phenotype of prostate cancer. Cancer Immunol Immunother 68(10):1621-1633

5. Gayther SA, de Foy KA, Harrington P, Pharoah P, Dunsmuir WD, Edwards SM et al (2000) The frequency of germ-line mutations in the breast cancer predisposition genes BRCA1 and BRCA2 in familial prostate cancer. The Cancer Research Campaign/British Prostate Group United Kingdom Familial Prostate Cancer Study Collaborators. Cancer Res 60(16):4513-4518

6. Levy-Lahad E, Friedman E (2007) Cancer risks among BRCA1 and BRCA2 mutation carriers. Br J Cancer 96(1):11-15

7. Lang SH, Swift SL, White H, Misso K, Kleijnen J, Quek RGW (2019) A systematic review of the prevalence of DNA damage response gene mutations in prostate cancer. Int J Oncol 55(3):597-616

8. Malone KE, Daling JR, Doody DR, Hsu L, Bernstein L, Coates RJ et al (2006) Prevalence and predictors of BRCA1 and BRCA2 mutations in a population-based study of breast cancer in white and black American women ages 35 to 64 years. Cancer Res 66(16):8297-8308

9. Agalliu I, Gern R, Leanza S, Burk RD (2009) Associations of high-grade prostate cancer with BRCA1 and BRCA2 founder mutations. Clin Cancer Res 15(3):1112-1120

10. Edwards SM, Dunsmuir WD, Gillett CE, Lakhani SR, Corbishley C, Young M et al (1998) Immunohistochemical expression of BRCA2 protein and allelic loss at the BRCA2 locus in prostate cancer. CRC/BPG UK Familial Prostate Cancer Study Collaborators. Int J Cancer 78(1):1-7

11. Francis JC, McCarthy A, Thomsen MK, Ashworth A, Swain A (2010) Brca2 and Trp53 deficiency cooperate in the progression of mouse prostate tumourigenesis. PLoS Genet 6(6):e1000995

12. Nyberg T, Frost D, Barrowdale D, Evans DG, Bancroft E, Adlard J et al (2020) Prostate cancer risks for male BRCA1 and BRCA2 mutation carriers: a prospective cohort study. Eur Urol 77(1):24-35

13. Okuku F, Orem J, Holoya G, De Boer C, Thompson CL, Cooney MM (2016) Prostate cancer burden at the Uganda cancer institute. J Glob Oncol 2(4):181-185

14. Yahaya J, Ajok F, Odida M, Wabinga H (2019) Androgen Receptor Overexpression in Patients With Prostate Cancer in Kampala Uganda. Am J Clin Pathol 152(1):86-87

15. Yahaya JJ (2019) Clinical and histopathological profile of patients with prostate cancer in Kampala Uganda. Med J Zambia 46(1):19-27 
16. Yahaya JJ, Okecha T, OdidaWabinga MH (2020) Prognostic factors for overall survival of patients with prostate cancer in Kyadondo County Uganda. Prostate Cancer 2020:1-9

17. Fiorentino M, Judson G, Penney K, Flavin R, Stark J, Fiore C et al (2010) Immunohistochemical expression of BRCA1 and lethal prostate cancer. Cancer Res 70(8):3136-3139

18. Giusti RM, Rutter JL, Duray PH, Freedman LS, Konichezky M, Fisher-Fischbein J et al (2003) A twofold increase in BRCA mutation related prostate cancer among Ashkenazi Israelis is not associated with distinctive histopathology. J Med Genet 40(10):787-792

19. Rabiau N, Dechelotte P, Adjakly M, Kemeny JL, Guy L, Boiteux JP et al (2011) BRCA1, BRCA2, AR and IGF-I expression in prostate cancer: correlation between RT-qPCR and immunohistochemical detection. Oncol Rep 26(3):695-702

20. Liu Q, Tong D, Liu G, Yi Y, Xu J, Yang X et al (2018) A novel BRCA2 mutation in prostate cancer sensitive to combined radiotherapy and androgen deprivation therapy. Cancer Biol Therapy 19(8):669-675

21. Gorodetska I, Kozeretska I, Dubrovska A (2019) BRCA genes: the role in genome stability, cancer stemness and therapy resistance. J Cancer 10(9):2109-2127

22. Risch HA, McLaughlin JR, Cole DE, Rosen B, Bradley L, Fan I et al (2006) Population BRCA1 and BRCA2 mutation frequencies and cancer penetrances: a kin-cohort study in Ontario Canada. J Natl Cancer Inst 98(23):1694-1706

23. Edwards SM, Kote-Jarai Z, Meitz J, Hamoudi R, Hope Q, Osin P et al (2003) Two percent of men with early-onset prostate cancer harbor germline mutations in the BRCA2 gene. Am J Hum Genet 72(1):1-12

24. Tryggvadottir $L$, Vidarsdottir $L$, Thorgeirsson $T$, Jonasson JG, Olafsdottir EJ, Olafsdottir GH et al (2007) Prostate cancer progression and survival in BRCA2 mutation carriers. J Natl Cancer Inst 99(12):929-935
25. Thorgeirsson T, Jordahl KM, Flavin R, Epstein MM, Fiorentino M, Andersson SO et al (2016) Intracellular location of BRCA2 protein expression and prostate cancer progression in the Swedish Watchful Waiting Cohort. Carcinogenesis 37(3):262-268

26. Kirchhoff T, Kauff ND, Mitra N, Nafa K, Huang H, Palmer C et al (2004) BRCA mutations and risk of prostate cancer in Ashkenazi Jews. Clin Cancer Res 10(9):2918-2921

27. Parkin DM, Nambooze S, Wabwire-Mangen F, Wabinga HR (2010) Changing cancer incidence in Kampala, Uganda, 1991-2006. Int J Cancer 126(5):1187-1195

28. Filella X, Fernandez-Galan E, Fernandez Bonifacio R, Foj L (2018) Emerging biomarkers in the diagnosis of prostate cancer. Pharmgenom Pers Med 11:83-94

29. Nevo A, Navaratnam A, Andrews P (2020) Prostate cancer and the role of biomarkers. Abdom Radiol (NY) 45(7):2120-2132

30. D'Amico AV, Chen MH, Roehl KA, Catalona WJ (2004) Preoperative PSA velocity and the risk of death from prostate cancer after radical prostatectomy. N Engl J Med 351(2):125-135

31. Martin NE, Mucci LA, Loda M, Depinho RA (2011) Prognostic determinants in prostate cancer. Cancer J 17(6):429-437

32. Thorne H, Willems AJ, Niedermayr E, Hoh IM, Li J, Clouston D et al (2011) Decreased prostate cancer-specific survival of men with BRCA2 mutations from multiple breast cancer families. Cancer Prev Res 4(7):1002-1010

33. Castro E, Goh C, Olmos D, Saunders E, Leongamornlert D, Tymrakiewicz $M$ et al (2013) Germline BRCA mutations are associated with higher risk of nodal involvement, distant metastasis, and poor survival outcomes in prostate cancer. J Clin Oncol 31(14):1748-1757

\section{Submit your manuscript to a SpringerOpen ${ }^{\odot}$ journal and benefit from:}

- Convenient online submission

- Rigorous peer review

- Open access: articles freely available online

- High visibility within the field

- Retaining the copyright to your article

Submit your next manuscript at springeropen.com 